\title{
Investigation into the Independent Metering Control Performance of a Twin Spools Valve with Switching Technology-controlled Pilot Stage
}

\author{
Qi Zhong ${ }^{1,2,3^{*}+}$, Huiming Bao ${ }^{1 \dagger}$, Yanbiao $\mathrm{Li}^{2,3}$, Haocen Hong ${ }^{1 *}$, Bin Zhang ${ }^{1}$ and Huayong Yang ${ }^{1}$
}

\begin{abstract}
In hydraulic area, independent metering control (IMC) technology is an effective approach to improve system efficiency and control flexibility. In addition, digital hydraulic technology (DHT) has been verified as a reasonable method to optimize system dynamic performance. Integrating these two technologies into one component can combine their advantages together. However, few works focused on it. In this paper, a twin spools valve with switching technology-controlled pilot stage (TSVSP) is presented, which applied DHT into its pilot stage while appending IMC into its main stage. Based on this prototype valve, a series of numerical and experiment analysis of its IMC performance with both simulated load and excavator boom cylinder are carried out. Results showed fast and robust performance of pressure and flow compound control with acceptable fluctuation phenomenon caused by switching technology. Rising time of flow response in excavator cylinder can be controlled within $200 \mathrm{~ms}$, meanwhile, the recovery time of rod chamber pressure under suddenly changed condition is optimized within $250 \mathrm{~ms}$. IMC system based on TSVSP can improve both dynamic performance and robust characteristics of the target actuator so it is practical in valvecylinder system and can be applied in mobile machineries.
\end{abstract}

Keywords: High speed on/off valve (HSV), Digital hydraulic technology (DHT), Switching pilot control, Twin spools valve, Independent metering control (IMC)

\section{Introduction}

Hydraulic systems are widely used in many applications because of its high power to weight ratio. Valve-controlled technology is one of the most common applied techniques in hydraulic area, but some shortcomings of traditional valve-controlled system such as lack of flexibility and robustness as well as slow response hind its wider applications. Therefore, some new technologies

\footnotetext{
*Correspondence: zhongqi@zjut.edu.cn; honghaocen@zju.edu.cn ${ }^{\dagger}$ Qi Zhong and Huiming Bao are co-first authors and they contributed to the work equally

${ }^{1}$ State Key Laboratory of Fluid Power and Mechatronic Systems, Zhejiang University, Hangzhou 310027, China

Full list of author information is available at the end of the article
}

such as IMC and DHT were developed aiming to solve these problems.

IMC technology breaks the mechanical connections between metering ports to separately control the load, so it can increase control degrees of freedom, making the system more flexible. Sitte et al. [[1]] reviewed IMC system structures, showing that different configurations of valve groups can be used to accomplish IMC, which can be roughly divided into two categories, configuration with two valves and four valves. Yao et al. [[2], [3]] constructed an IMC system with four cartridge valves which were arranged in a Wheatstone bridge configuration, proposed IMC system showed fast cylinder speed and good system pressure performance. Opdenbosch et al. [[4]] developed a valve group which consists of 
four electro-hydraulic poppet valves to accomplish IMC system, experimental results demonstrated that the proposed valve arrangement can precisely control the motion of the hydraulic actuator. Lyu et al. [[5]] developed an IMC system with good energy saving performance based on four proportional valves. Four-valves configurated IMC systems mentioned above showed good results in dynamic characteristics and energy saving performance. However, compared with traditional directional valves, four-valves configurated IMC systems occupy so much space while making the control algorithm more complex, therefore two-valves configuration are adopted in some researches to realize IMC. Chen et al. [[6]] built an IMC system composed of two directional valves, good trajectory tracking performance was achieved. Xu et al. constructed a pump/valves coordinate IMC system using two proportional valves to control a cylinder, results showed that dual objectives of energy saving and control performance improvement [[7]] as well as oscillation reduction [[8]] were able to be achieved with the proposed IMC system. Liu et al. [[9], [10]] applied two valves to study IMC technology, pressure and flow accordance control of single cylinder as well as velocity and position control of dual cylinders [[11]] were studied, experiment results showed the superiority of IMC in excavator arms control. Ba et al. [[12]] proposed a novelty force control method for a hydraulic drive system, this method rearranges the dynamic compliance of force control system and has excellent control effect.

As mentioned above, four-valves configuration is more complex and space-occupying, so its IMC systems are not suitable for mobile machineries, such as excavators which have high requirement for lightweight. Hence, two-valves configuration is the most used IMC structure in researches on mobile machineries. Furthermore, integrating two spools into one valve is a better approach to reduce weight of the IMC system.

Digital hydraulic technology (DHT) means hydraulic systems having discrete valued components actively controlling system output [[13]]. HSV is a typical digital hydraulic component, which can produce fluid in discrete state. When HSV works under high frequency, fluid produced by HSV can be approximated as continuous fluid. HSV has fast dynamic characteristics, relatively small flow and strong anti-pollution ability, which exactly meet the demands for pilot stage of hydraulic components, making it a better choice for valve pilot stage compared with traditional proportional pilot valve. Winkler et al. [[14]] firstly proposed a novel multi poppet valve piloted by HSV which can fulfill the valve main stage demands for small switching time and high fatigueendurable operating frequency. Wen et al. [[15]] studied spool displacement and outlet flow of cartridge valve controlled by HSV, and results showed that proposed cartridge valve can achieve good linear control performance when the input signal is in low-frequency and moderate duty cycle state. Li et al. [[16]] studied the fluctuation characteristics of HSV pilot-controlled flow valve, showing that mean outlet flow can be proportionally controlled by adjustment of the operation duty ratio of HSV. Wang et al. [[17]] investigated the dynamic performance of directional valve when proportional pilot stage is replaced by HSVs, the displacement tracking study of hydraulic cylinder showed that the maximum error can be controlled within $\pm 150 \mu \mathrm{m}$. All mentioned literatures verified that HSV is suitable for valve pilot stage and can achieve good dynamic performance. Shi et al. [[18]] studied hydraulic switching valve driven by magnetic shape memory alloy, its results show that the studied valve can achieve fast response with opening time of $5 \mathrm{~ms}$; Zhong et al. [[19]] proposed a pre-existing control algorithm (PECA) to improve the dynamic characteristics of the HSV, and simultaneously optimize the power losses of the HSV to improve its energy conversion efficiency; both of them provide theoretical supports for the development of pilot stage hydraulic switching valve.

As using two HSVs as pilot stage to control one single spool valves is practicable, applying four HSVs for the pilot stage of a twin spools valve to construct IMC system is feasible. With these in mind, the contribution of this paper is to propose a twin spools valve with switching technology-controlled pilot stage (TSVSP) and study its IMC performance.

The rest of this paper is organized as follows: the structure of the mentioned valve and its mathematical model are introduced firstly in Section 2, followed by a description of control algorithm architecture described in Section 3. Experimental and numerical results are given in Section 4 followed by the conclusions of the paper.

\section{Configuration and Modeling of TSVSP}

\subsection{Structure of the TSVSP}

TSVSP proposed in this paper adopts four two-land and three-way HSVs on its pilot stage, every two HSVs are used to control one main spool, as shown in Figures 1 and 2. By adjusting the operation duty ratio of HSVs, pressure of control chambers at both ends of the main valve spool can be modulated, thereby changing the displacement of the main valve spool.

\subsection{TSVSP Dynamics Model}

For ease of description, four pilot HSVs are named as HSV1, HSV2, HSV3 and HSV4, while two main stage valves are named main valve1 and main valve2, respectively, as shown in Figure 2. Since TSVSP is symmetrical, 


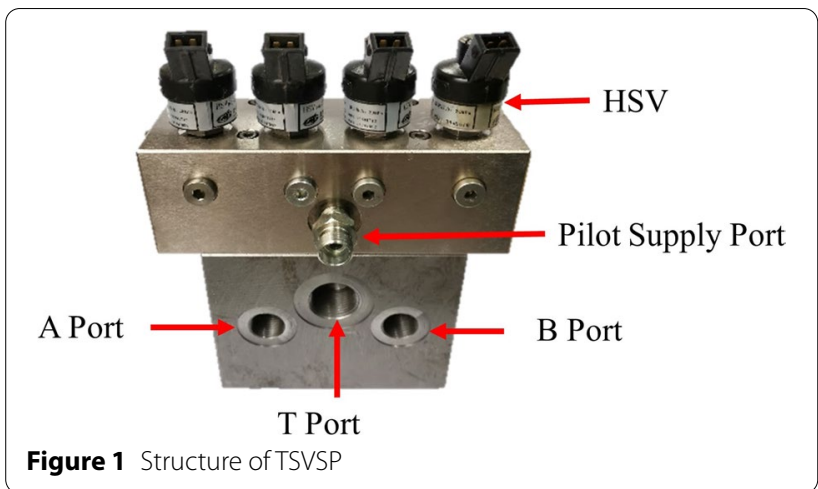

two main valves and their corresponding pilot stages have the same structure. Therefore, the mathematical modeling analysis of TSVSP in Section 2.2 is based on the left main spool and its pilot stage, which includes HSV1, HSV2 and main valve1.

When the operation duty ratio of HSV1 is higher than that of HSV2, pressure in left control chamber of the main valve1 will be higher than the pressure in its right chamber, then main valve1 will move to the right. On the contrary, when the operation duty ratio of HSV2 is higher than that of HSV1, main valve1 spool will move to the left.

\subsubsection{Pilot Stage Theoretical Analysis}

The configuration of the pilot HSV used in this paper is shown in Figure 3, and direction of oil flow changes according to its on and off state.

The flow through the operation port of HSV1 can be expressed as:

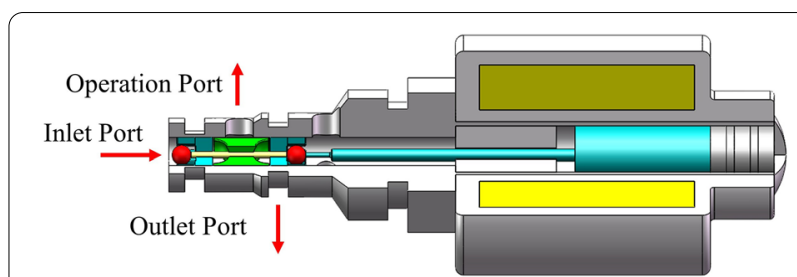

Figure 3 Structure of HSV

$$
\begin{aligned}
& Q_{1 \mathrm{p}}=C_{d} A_{1 \mathrm{p}} \sqrt{2\left(P_{s \mathrm{p}}-P_{11}\right) / \rho}, \\
& Q_{1 \mathrm{n}}=C_{d} A_{1 \mathrm{n}} \sqrt{2\left(P_{11}-P_{\mathrm{t}}\right) / \rho},
\end{aligned}
$$

where $Q_{1 \mathrm{p}}$ and $Q_{1 \mathrm{n}}$ are the flow of HSV1 in the opened and closed state, respectively; $A_{1 \mathrm{p}}$ and $A_{1 \mathrm{n}}$ are the effective opening area of the HSV1 inlet port and outlet port, respectively; $C_{\mathrm{d}}$ is flow coefficient, while $\rho$ is oil density; $P_{\mathrm{sp}}, P_{11}$, and $P_{\mathrm{t}}$ are the pressure of supply port, HSV1 operation port and tank, respectively. The effective opening area of HSV1 is given by:

$$
\begin{aligned}
& A_{1 \mathrm{p}}= \pi d_{1} x_{\mathrm{v} 1}\left(\sqrt{\left(\frac{D}{2}\right)^{2}-\left(\frac{d_{1}}{2}\right)^{2}}+\frac{x_{\mathrm{v} 1}}{2}\right) \\
& / \sqrt{\left(\frac{d_{1}}{2}\right)^{2}+\left(\sqrt{\left(\frac{D}{2}\right)^{2}-\left(\frac{d_{1}}{2}\right)^{2}}+x_{\mathrm{v} 1}\right)^{2}}
\end{aligned}
$$

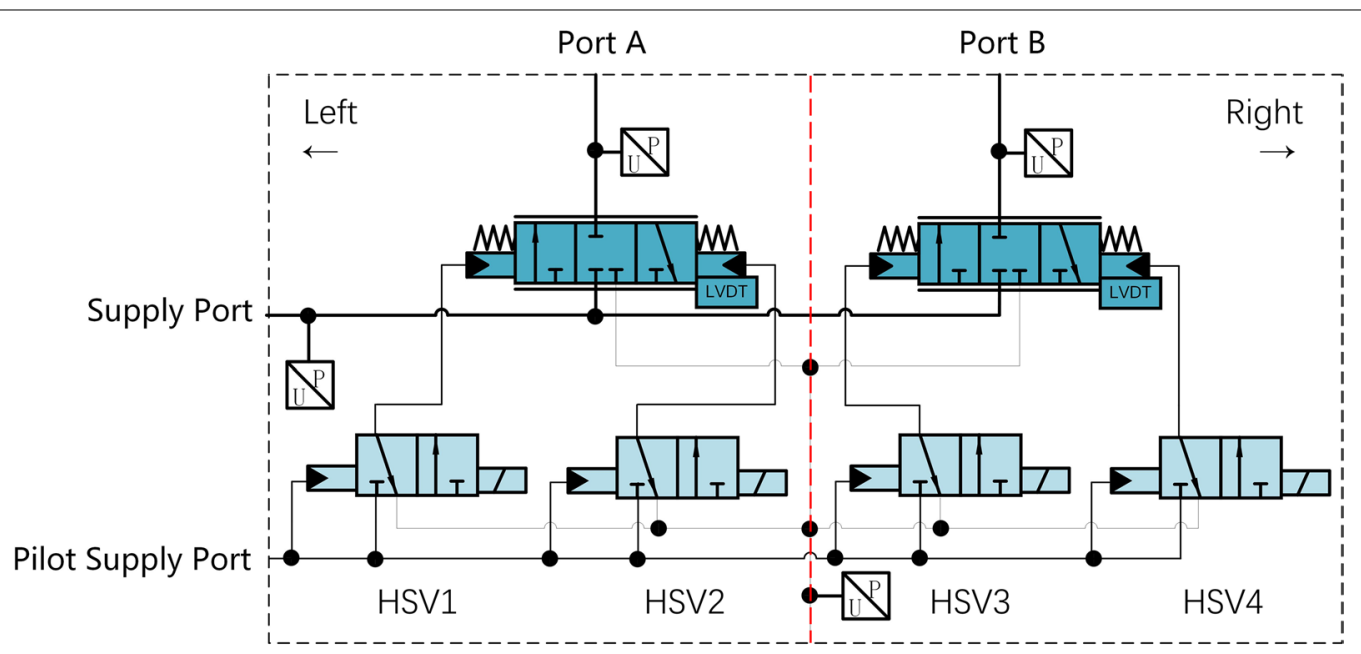

Figure 2 Schematic of TSVSP

Tank Port 


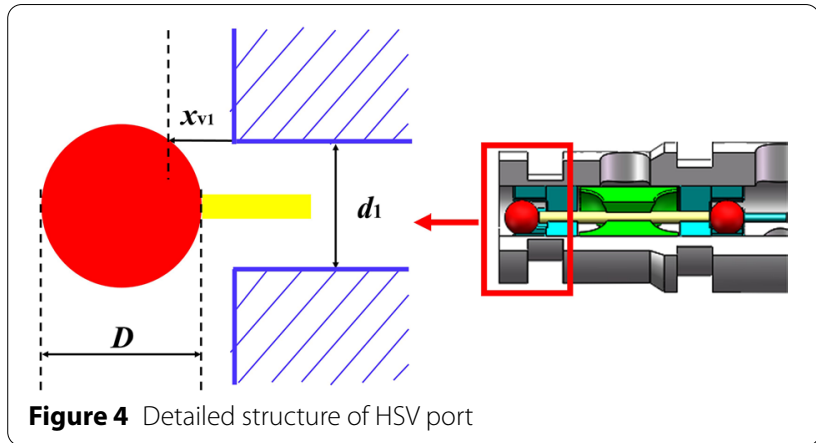

$$
\begin{array}{r}
A_{1 \mathrm{n}}=\pi d_{1}\left(l-x_{\mathrm{v} 1}\right)\left(\sqrt{\left(\frac{D}{2}\right)^{2}-\left(\frac{d_{1}}{2}\right)^{2}}+\frac{l-x_{\mathrm{v} 1}}{2}\right) \\
\quad / \sqrt{\left(\frac{d_{1}}{2}\right)^{2}+\left(\sqrt{\left(\frac{D}{2}\right)^{2}-\left(\frac{d_{1}}{2}\right)^{2}}+l-x_{\mathrm{v} 1}\right)^{2}}
\end{array}
$$

where $x_{\mathrm{v} 1}$ is armature displacement of HSV1, $D$ is diameter of its operation ball; $d_{1}$ is its orifice diameter as shown in Figure $4 ; l$ is the stroke of HSV1.

Similarly, the flow through the pilot HSV2 can be expressed as:

$$
\begin{aligned}
& Q_{2 \mathrm{p}}=C_{d} A_{2 \mathrm{p}} \sqrt{2\left(P_{s \mathrm{p}}-P_{12}\right) / \rho}, \\
& Q_{2 \mathrm{n}}=C_{d} A_{2 \mathrm{n}} \sqrt{2\left(P_{12}-P_{\mathrm{t}}\right) / \rho},
\end{aligned}
$$

where $Q_{2 \mathrm{p}}$ and $Q_{2 \mathrm{n}}$ are flow of HSV2 in the opened state and the closed state; $A_{2 \mathrm{p}}$ and $A_{2 \mathrm{n}}$ are the effective opening area of the HSV2 oil inlet port and outlet port; $P_{12}$ is pressure of HSV2 operation port.

When the pilot HSV1 switches with high frequency, the discrete fluid generated by HSV1 can be approximated as continuous fluid, whose average flow can be computed from

$$
\overline{Q_{1}}=\frac{Q_{1 \mathrm{p}} t_{1 \mathrm{on}}-Q_{1 \mathrm{n}} t_{1 \mathrm{off}}}{t_{1 \mathrm{on}}+t_{1 \mathrm{off}}}
$$

where $\overline{Q_{1}}$ is average flow of HSV1, $t_{1 \text { on }}$ and $t_{1 \text { off }}$ respectively represent the opened time and closed time of HSV1 in one single switching cycle. Due to the electrical inertia, magnetic inertia and mechanical inertia in the pilot HSV, there will be a delay between the control signal and its actual movement.

As shown in Figure 5, when opening target comes, it takes some opening delay time $\left(t_{\text {don }}\right)$ to start moving and some opening movement time $\left(t_{\text {mon }}\right)$ to reach fully opened state; meanwhile, in the closing process, it also needs some closing delay time $\left(t_{\text {doff }}\right)$ to start closing and

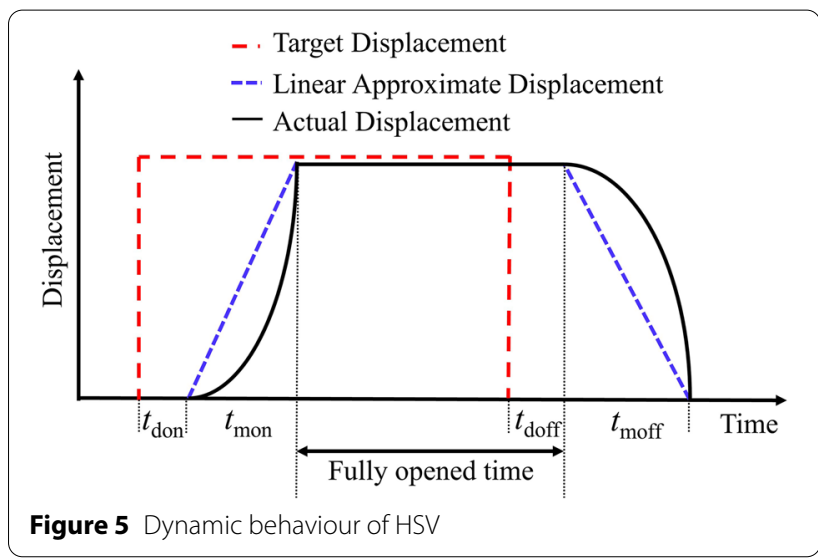

some closing movement time $\left(t_{\text {moff }}\right)$ to reach fully closed state. From a macro perspective, the opening and closing movement of HSV1 can be approximated as a linear movement, so $t_{1 \text { on }}$ and $t_{1 \text { off }}$ can be derived:

$$
\begin{aligned}
& t_{1 \mathrm{on}}=\frac{1}{f_{1}} D_{1}-t_{1 \mathrm{don}}-\frac{1}{2} t_{1 \mathrm{mon}}+t_{1 \mathrm{doff}}+\frac{1}{2} t_{1 \mathrm{moff}}, \\
& t_{1 \mathrm{off}}=\frac{1}{f_{1}}\left(1-D_{1}\right)+t_{1 \mathrm{don}}+\frac{1}{2} t_{1 \mathrm{mon}}-t_{1 \mathrm{doff}}-\frac{1}{2} t_{1 \mathrm{moff}},
\end{aligned}
$$

where $f_{1}$ is control signal frequency of HSV1; $D_{1}$ is the duty ratio of HSV1 control signal; $t_{1 \text { don }}, t_{1 \text { mon }}, t_{1 \text { doff }}$ and $t_{1 \text { moff }}$ represent the opening delay time, opening movement time, closing delay time and closing movement time of HSV1 respectively, which will not be affected by the variation of $f_{1}$. As a result, when $f_{1}$ increases, proportion of fully opened time in the whole duty cycle becomes smaller while dead and saturation zone becomes larger, this will result in smaller percentage of controllable part in whole HSV duty cycle. What's more, when $f_{1}$ is too small, pressure fluctuation will be caused. These will affect the control performance, so the control signal frequency of the pilot HSVs should be set within a reasonable range.

Driven by the discrete digital fluid, the pressure in the left and right chambers of the main valve1 spool can be expressed as:

$$
\left\{\begin{array}{l}
\frac{\mathrm{d} P_{11}}{\mathrm{~d} t}=\frac{\beta}{V_{11}}\left(Q_{1 \mathrm{v}}-A_{\mathrm{m}} \frac{\mathrm{d} x_{1}}{\mathrm{~d} t}\right), \\
\frac{\mathrm{d} P_{12}}{\mathrm{~d} t}=\frac{\beta}{V_{12}}\left(A_{\mathrm{m}} \frac{\mathrm{d} x_{1}}{\mathrm{~d} t}-Q_{2 \mathrm{v}}\right),
\end{array}\right.
$$

where $Q_{1 \mathrm{v}}$ and $Q_{2 \mathrm{v}}$ are the flow of HSV1 and HSV2, which can be calculated from Eqs. (1)-(6); $\beta$ is bulk modulus; $A_{\mathrm{m}}$ is effective cross-sectional area of the main valve1 


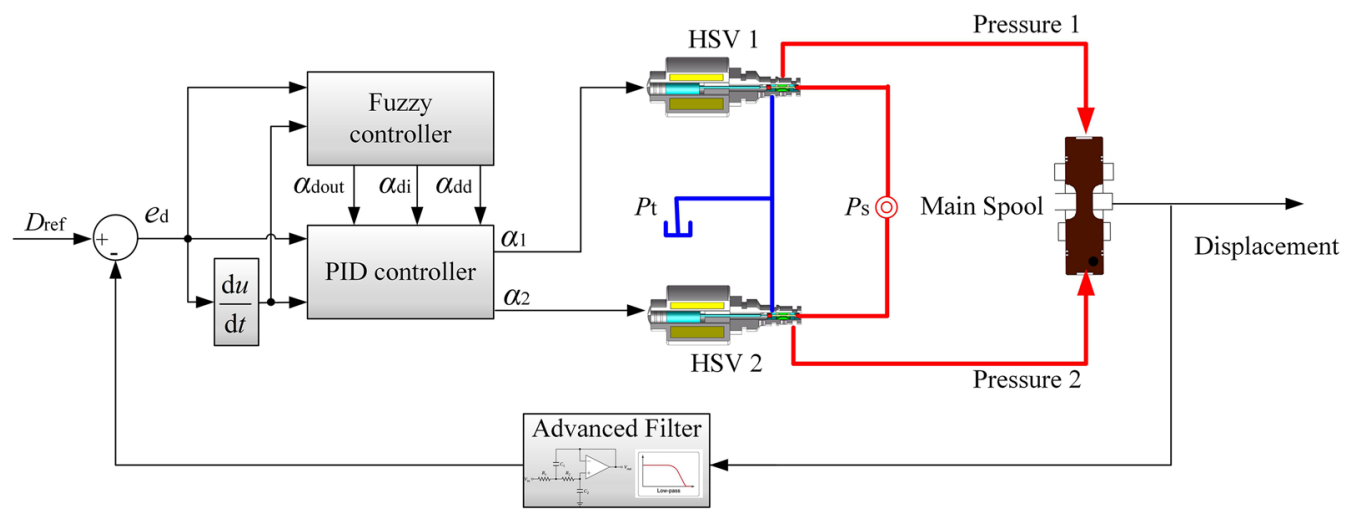

Figure 6 Spool position control structure

spool; $V_{11}$ and $V_{12}$ are volumes of main valve1 spool left chamber and right chamber; $x_{1}$ is displacement of the main valve1.

\subsubsection{Main Stage Theoretical Analysis}

According to Newton's second law, the motion equation of the main valve 1 spool is

$$
\left\{\begin{array}{l}
\dot{\boldsymbol{x}}=\boldsymbol{A}_{2} \boldsymbol{x}+\boldsymbol{B}_{2} \boldsymbol{u}+\boldsymbol{M}_{2} \boldsymbol{F}_{\boldsymbol{m}}, \\
y=x_{1}, \\
\boldsymbol{A}_{2}=\left[\begin{array}{cc}
0 & 1 \\
-\frac{K_{1}}{M_{\mathrm{m}}} & -\frac{B_{\mathrm{m}}}{M_{\mathrm{m}}}
\end{array}\right], \boldsymbol{x}=\left[\begin{array}{l}
x_{1} \\
\dot{x}_{1}
\end{array}\right], \boldsymbol{F}_{\boldsymbol{m}}=\left[\begin{array}{c}
0 \\
F_{m}
\end{array}\right], \\
\boldsymbol{B}_{2}=\left[\begin{array}{c}
0 \\
\frac{A_{\mathrm{m}}}{M_{\mathrm{m}}}
\end{array}\right], \boldsymbol{u}=\left[\begin{array}{l}
0 \\
P_{11}-P_{12}
\end{array}\right], \boldsymbol{M}_{2}=\left[\begin{array}{c}
0 \\
\frac{-1}{M_{\mathrm{m}}}
\end{array}\right],
\end{array}\right.
$$

where $M_{\mathrm{m}}$ is the mass of the main valve1 moving parts; $F_{\mathrm{m}}$ is the flow force applied on the main valvel spool; $K_{1}$ is spring coefficient of the main valve 1 spool; $B_{\mathrm{m}}$ is damping coefficient when the main valve1 spool moves. Among them, the flow force applied on the main valve1 spool can be expressed as:

$$
F_{\mathrm{m}}=F_{\mathrm{ms}}+F_{\mathrm{mt}},
$$

where $F_{\mathrm{ms}}$ is the steady flow force applied on the main valve1 spool

$$
F_{\mathrm{ms}}=2 W_{\mathrm{m}} C_{\mathrm{d}} C_{\mathrm{v}} \cos (\theta) \Delta P_{\mathrm{m}} x_{1},
$$

$F_{\mathrm{mt}}$ is the transient flow force applied on the main valve1 spool

$$
F_{\mathrm{mt}}=W_{\mathrm{m}} C_{\mathrm{d}} l_{\mathrm{m}} \sqrt{2 \rho \Delta P_{\mathrm{m}}} \frac{\mathrm{d} x_{1}}{\mathrm{~d} t},
$$

where $W_{m}$ is area gradient of the main valve1; $\Delta P_{m}$ is valve port pressure difference of the main valve 1 , and $l_{m}$ is the flow length of the oil in the main valve1.
According to the flow continuity equation, the pressure of the main valve1 control chamber can be obtained:

$$
\left\{\begin{array}{l}
\frac{\mathrm{d} P_{11}}{\mathrm{~d} t}= \begin{cases}\frac{\beta}{V_{11}}\left(Q_{\mathrm{p} 1}-A_{\mathrm{m}} \frac{\mathrm{d} x_{1}}{\mathrm{~d} t}\right) & x_{\mathrm{p} 1} \geq 0, \\
\frac{\beta}{V_{11}}\left(A_{\mathrm{m}} \frac{\mathrm{d} x_{1}}{\mathrm{~d} t}-Q_{\mathrm{p} 1}\right) & x_{\mathrm{p} 1}<0,\end{cases} \\
\frac{\mathrm{d} P_{12}}{\mathrm{~d} t}= \begin{cases}\frac{\beta}{V_{12}}\left(Q_{\mathrm{p} 2}-A_{\mathrm{m}} \frac{\mathrm{d} x_{1}}{\mathrm{~d} t}\right) & x_{\mathrm{p} 1}<0, \\
\frac{\beta}{V_{12}}\left(A_{\mathrm{m}} \frac{\mathrm{d} x_{1}}{\mathrm{~d} t}-Q_{\mathrm{p} 2}\right) & x_{\mathrm{p} 1} \geq 0 .\end{cases}
\end{array}\right.
$$

Taking it as an example that main valve1 is connected to supply pressure while main valve 2 is connected to tank, flow of main stage valves can be derived

$$
\begin{cases}Q_{1}=C_{d} W_{\mathrm{m}} x_{1} \sqrt{2\left(P_{s}-P_{1}\right) / \rho} & x_{1} \geq 0, \\ Q_{2}=C_{d} W_{\mathrm{m}} x_{2} \sqrt{2\left(P_{2}-P_{\mathrm{t}}\right) / \rho} & x_{2}<0,\end{cases}
$$

where $x_{2}$ is displacement of main valve2 spool, $P_{s}$ is oil supply pressure of the system, $P_{1}$ and $P_{2}$ are the pressure of the load inlet and outlet chambers, respectively.

\section{Control Algorithm}

\subsection{Valve Control Algorithm}

Due to high-frequency switching of the pilot HSVs, there will be unavoidable fluctuation phenomenon of the main valve spool displacement, and finally cause pressure and flow jitter, so low pass filters are added to reduce the effect of these fluctuation.

Fuzzy PID control algorithm is applied for the spool displacement control, as shown in Figure 6 . In this position fuzzy controller, both $e_{d}(k)$ and $\Delta e_{d}(k)$, which can be equivalent to spool displacement and velocity, respectively, are considered as variable inputs.

From Figure 7, when duty ratio of HSVs are between $20 \%$ and $90 \%$, linearity between flow and duty ratio is the best.

Set intermediate value $55 \%$ as the initial duty ratio of pilot HSV, the control signal duty ratios of HSV1 and HSV2 can be expressed 


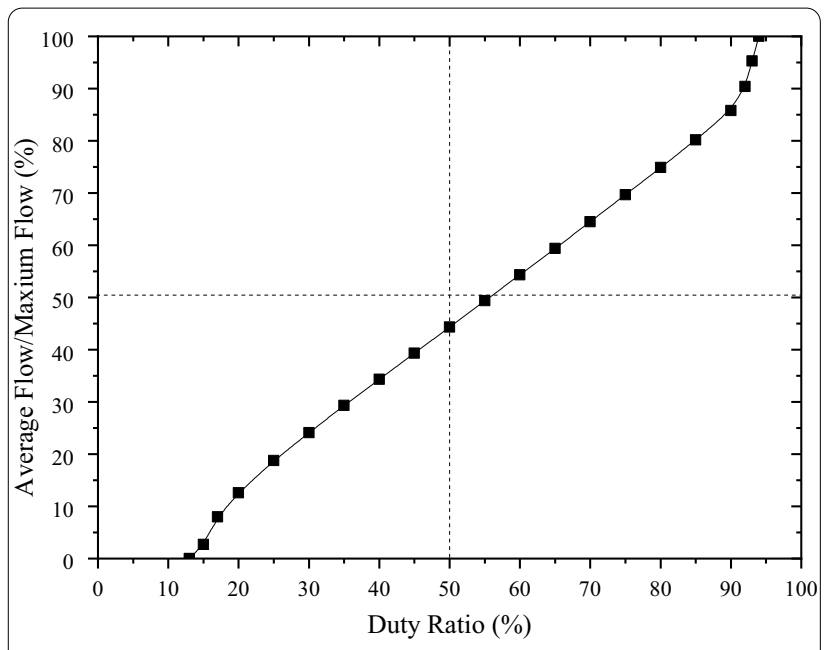

Figure 7 Flow of HSV under different duty cycle

$$
\begin{aligned}
a_{1}= & 0.55-a_{\text {dout }}\left\{k_{p} e_{d}(k)+a_{d i} k_{i} \sum_{i=0}^{k}\left[e_{d}(i)\right]\right. \\
& \left.+a_{d d} k_{d}\left[e_{d}(k)-e_{d}(k-1)\right]\right\} \\
a_{2}= & 0.55+a_{\text {dout }}\left\{k_{p} e_{d}(k)+a_{d i} k_{i} \sum_{i=0}^{k}\left[e_{d}(i)\right]\right. \\
& \left.+a_{d d} k_{d}\left[e_{d}(k)-e_{d}(k-1)\right]\right\}
\end{aligned}
$$

\subsection{Experiment on System Pressure and Flow Control}

Firstly, for basic algorithm test, a two-way pressure valve is used as load to conduct the pressure and flow control simulated experiment, which can optimize the

where $\alpha_{1}$ and $\alpha_{2}$ are control signal duty ratios of HSV1 and HSV2; $k_{p}, k_{i}$ and $k_{d}$ are the parameters of the PID controller; $\alpha_{d o u}, \alpha_{d i}$ and $\alpha_{d d}$ are the outputs of the displacement fuzzy controller.

\subsection{System Control Algorithm}

A pair of two-level fuzzy controller is applied to improve system flow and pressure dynamic performance, as shown in Figure 8. Detailed illustration of system control algorithm can be found in Ref. [[20]].

\section{Simulate and Experiment Analysis}

The schematic of pressure and flow control testbed is shown in Figure 9. Main valve1 is used to control inlet chamber of cylinder while main valve2 is used to control outlet chamber. Based on the testbed, simulation model is constructed as shown in Figure 10. SC_1 stands for HSV control algorithm in Ref. [[21]], SC_2 stands for control algorithm described in Eqs. (17) and (18). To improve the optimization effect, parameters of Fuzzy PID controllers are firstly optimized through experiments based on a simulated load. According to the actual working condition of tested excavator boom cylinder, hydraulic system flow is set to $60 \mathrm{~L} / \mathrm{min}$ while system pressure is set to $10 \mathrm{MPa}$.



Figure 8 System control algorithm structure 


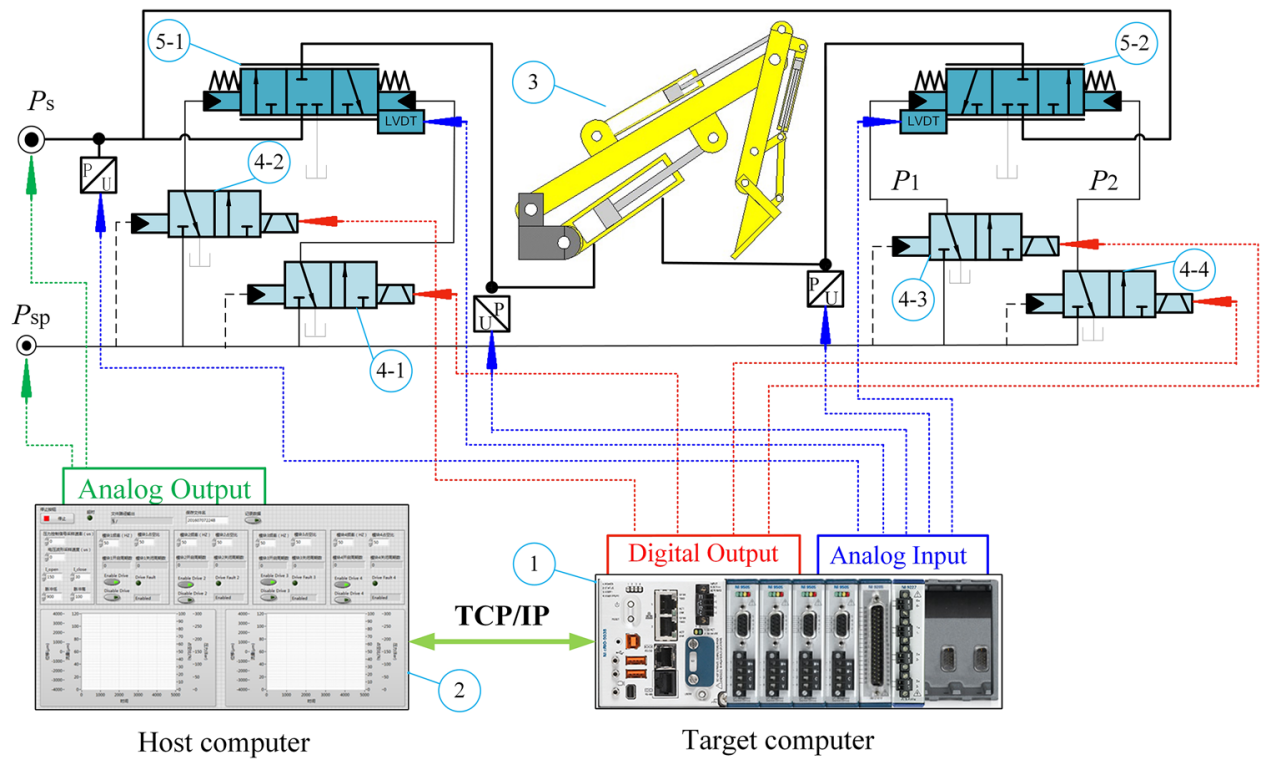

Figure 9 Pressure and flow control testbed schematic. 1. Target computer, 2. Host computer, 3.Load part, 4. Piolt HSV, 5. Main stage valve

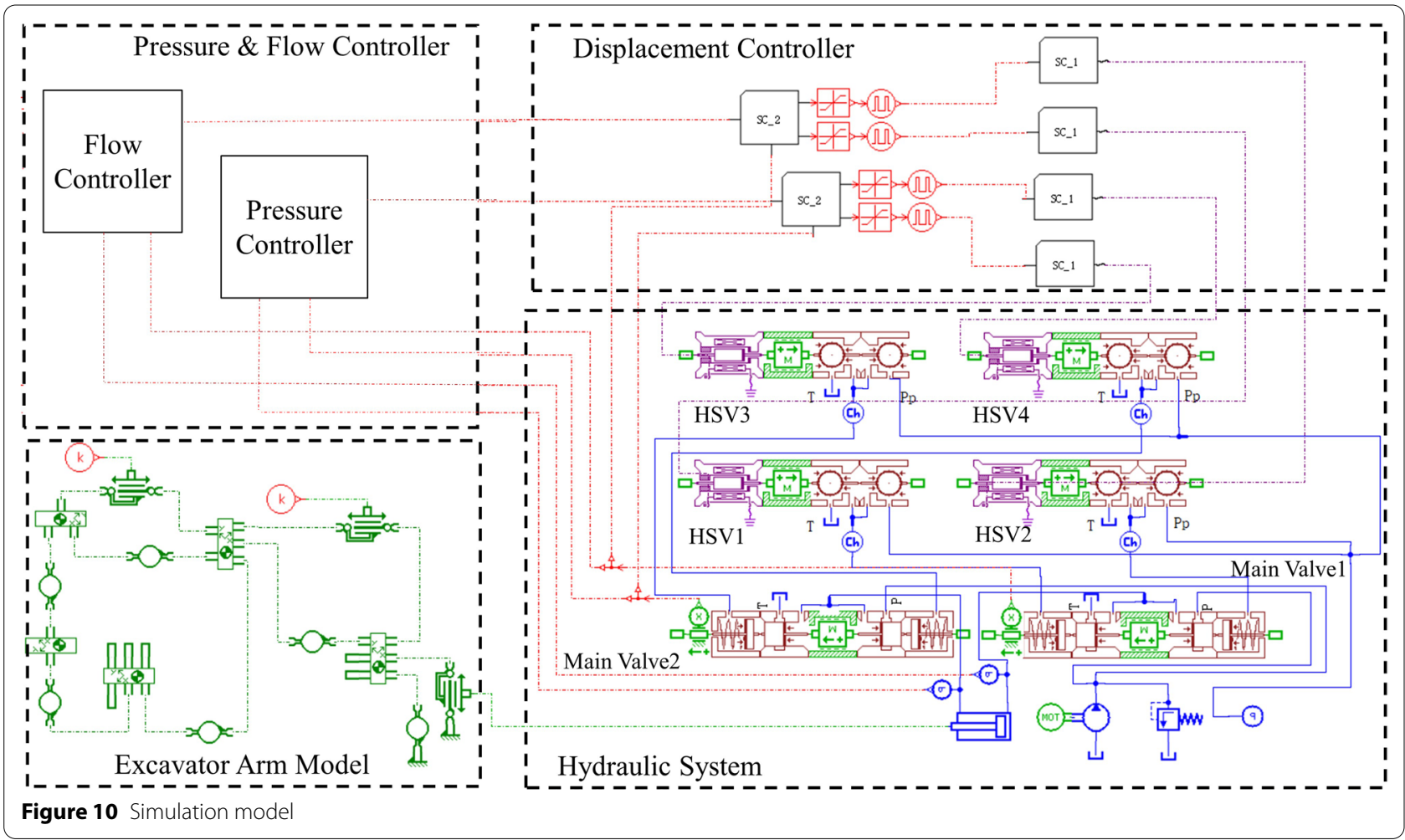

appropriate parameters for pressure controller as well as flow controller.

\subsubsection{Experimental Test on Pressure Control}

According to working condition of excavator arms, it is found that $0.5 \mathrm{MPa}$ to $6 \mathrm{MPa}$ is a common pressure range of boom cylinder chambers in working duty cycles, which is chosen as test range for pressure control. 


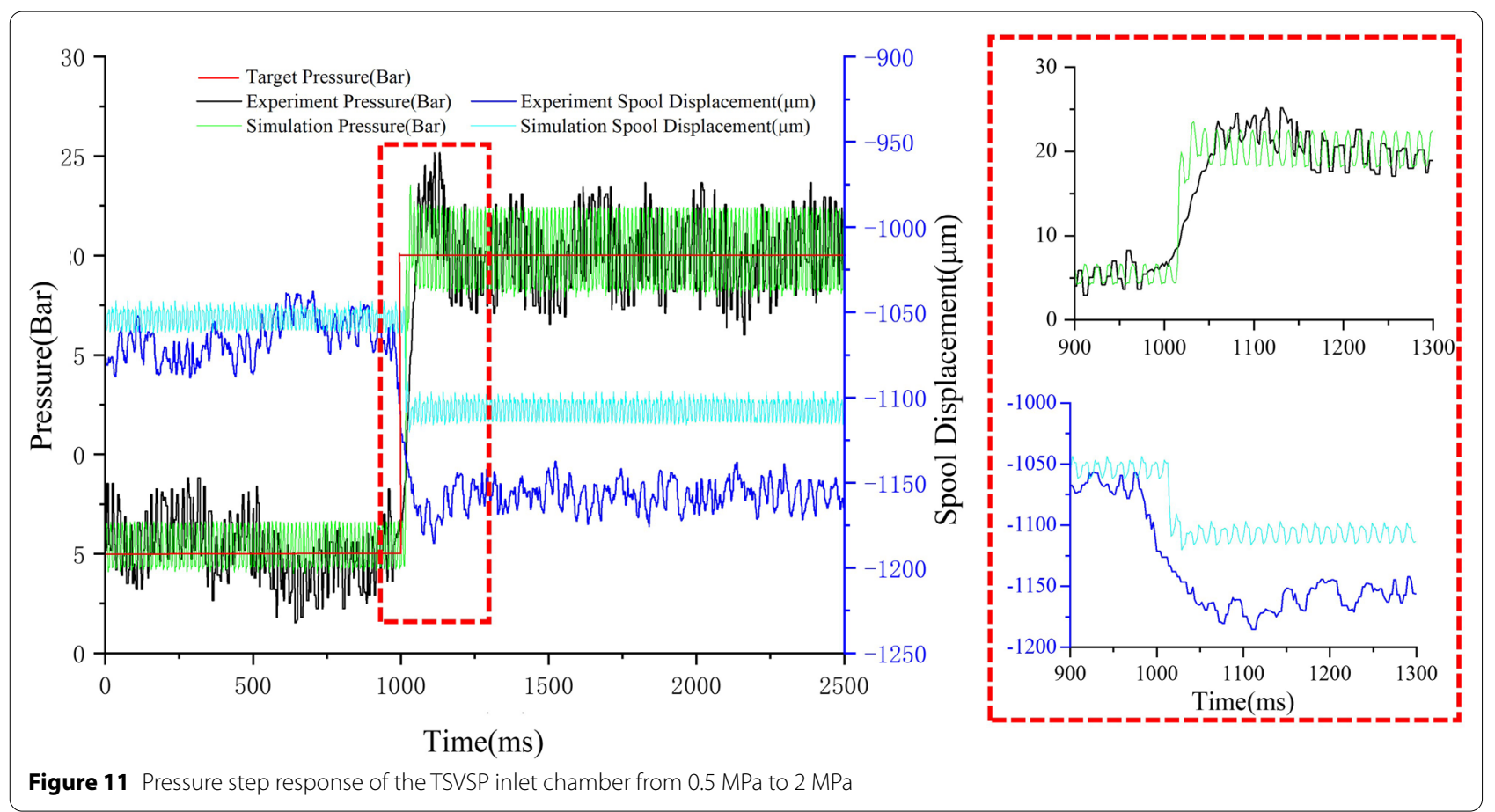

TSVSP inlet chamber pressure control is conducted as shown in Figures 11 and 12. Dead zone of main valve is $1000 \mu \mathrm{m}$; based on the experiment results, displacement of main valve 2 spool is set as $3000 \mu \mathrm{m}$ to reduce the throttle loss during inlet pressure control experiment.
The stabilization time of step response from 0.5 MPa to $2 \mathrm{MPa}$ is $150 \mathrm{~ms}$, while time required for $2 \mathrm{MPa}$ to $5 \mathrm{MPa}$ response is about $120 \mathrm{~ms}$, the pressure overshoot is less than $12 \%$. Corresponding simulation results showed comparable results. Meanwhile, due to simulation
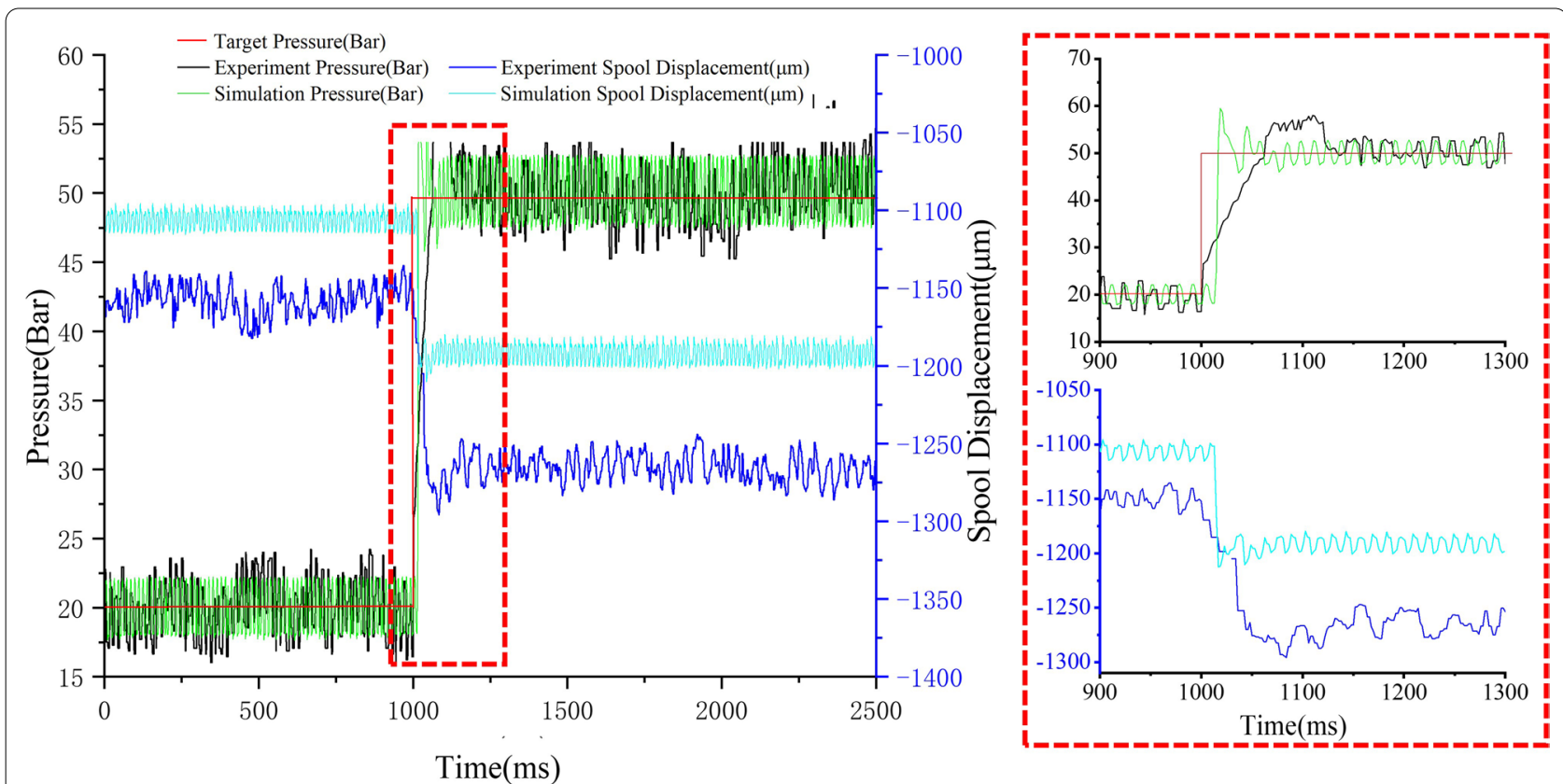

Figure 12 Pressure step response of the TSVSP inlet chamber from $2 \mathrm{MPa}$ to $5 \mathrm{MPa}$ 

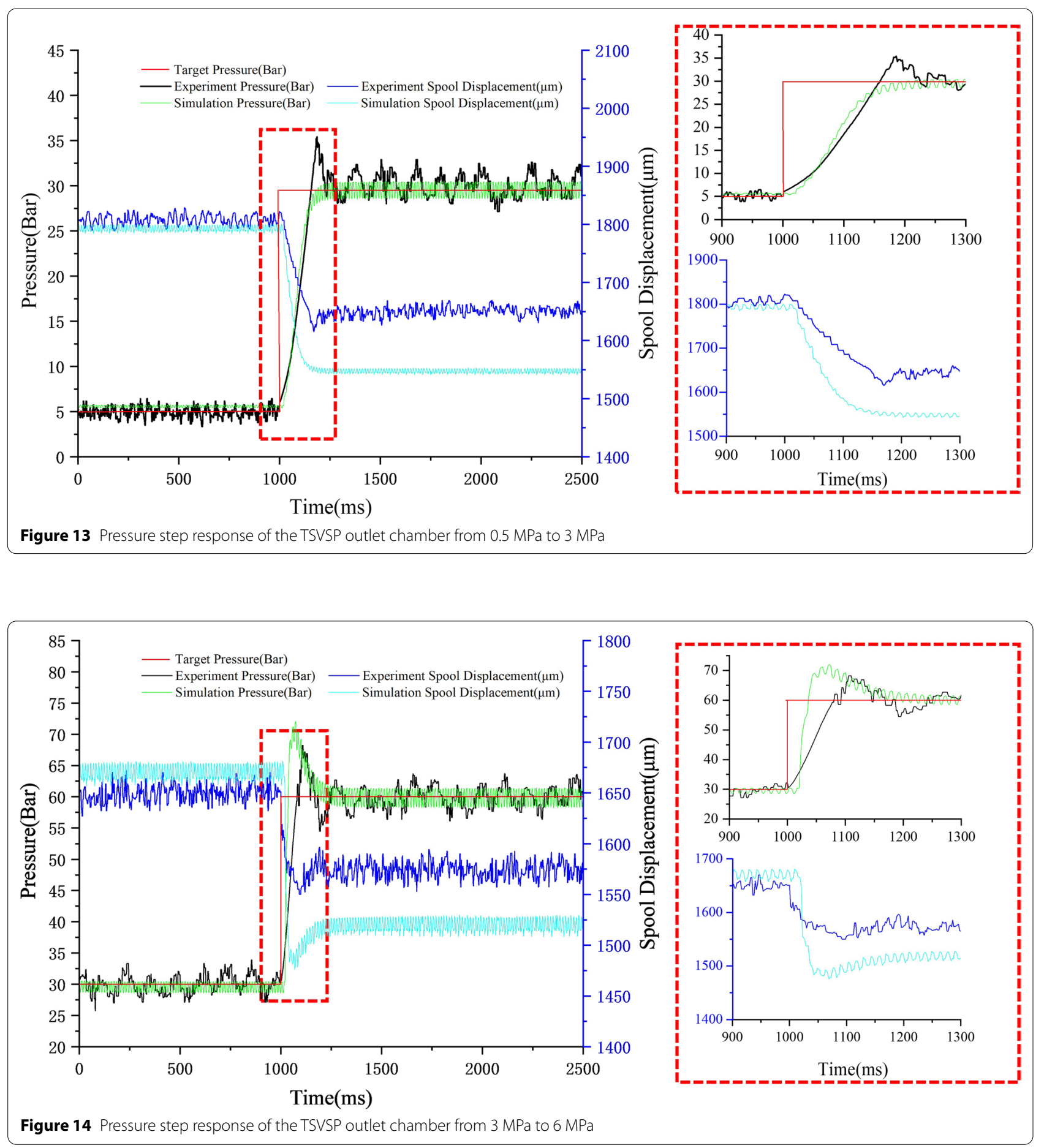

modeling error and nonlinearity of displacement sensors, a discrepancy occurs between spool displacements of simulation and test.

Pressure control of outlet chamber is commonly used to decrease the back pressure of actuator to reduce the system throttling loss while improve the system efficiency. Sometimes in order to optimize the dynamic characteristics of actuator, it is necessary to increase the back pressure to improve system damping. Therefore, dynamic performance of back pressure has a huge impact on the energy-saving characteristics of the system as well as the kinetic characteristic of the actuator. Based on 


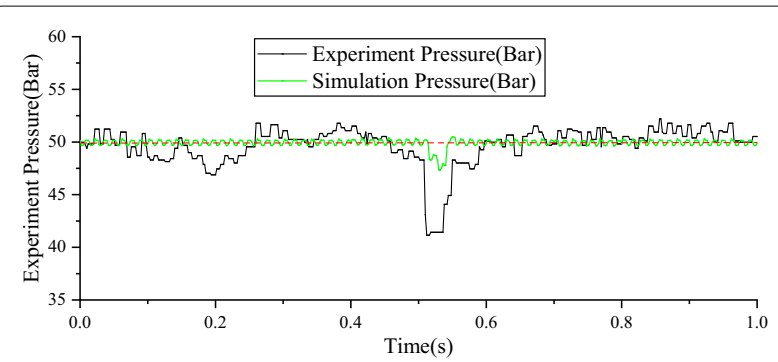

Figure 15 Backpressure control performance under flow decrease

some typical backpressure changing conditions, results of the backpressure control experiment is shown in Figures 13 and 14, during which main valve1 spool stays at $-3000 \mu \mathrm{m}$ to reduce the throttle loss of main valve1.

The stabilization time required for backpressure to step from $0.5 \mathrm{MPa}$ to $3 \mathrm{MPa}$ is about $200 \mathrm{~ms}$, and the overshoot reaches $0.54 \mathrm{MPa}$. When the backpressure is controlled to step from $3 \mathrm{MPa}$ to $6 \mathrm{MPa}$, the overshoot is about $0.8 \mathrm{MPa}$ and the stabilization time is $180 \mathrm{~ms}$. Corresponding simulation results showed similar results.

According to the backpressure curve in Figures 13 and 14 , although the main spool has the same jitter characteristics under different back pressure, when the back pressure is controlled near $0.5 \mathrm{MPa}$, pressure fluctuation is only about $0.3 \mathrm{MPa}$, while when the back pressure stabilizes at a higher pressure value, the back pressure jitter is relatively more severe. Taking back pressure of $3 \mathrm{MPa}$ and $6 \mathrm{MPa}$ as an example, the pressure fluctuation is stable at about $0.6 \mathrm{MPa}$. The main reason for this phenomenon is that the main spool has different flow gains at different positions. When the system backpressure is maintained at a smaller value, its jitter range is also smaller.

In order to improve the pressure control characteristics of TSVSP under changing load, experimental studies are carried out. The experiment on pressure control performance of the outlet chambers under flow step are shown in Figures 15 and 16. Main valve1 spool displacement is set to $-2500 \mu \mathrm{m}$ for the same reason as backpressure control experiment, while main valve2 is set as the pressure control mode to stabilize the backpressure at $5 \mathrm{MPa}$ at the beginning. Firstly, the displacement command of the main valve1 is updated to $-2000 \mu \mathrm{m}$ to reduce the flow. At this time, the backpressure characteristic is shown in Figure 15. The backpressure fluctuation is less than $0.98 \mathrm{MPa}$, and the pressure recovery time is also about $55 \mathrm{~ms}$. Similarly, update the displacement command of the main valve 1 to $-2500 \mu \mathrm{m}$ to increase the flow as shown in Figure 16, Due to the change in flow, the outlet throttling increases, so the backpressure suddenly increases. The pressure fluctuation is about $1 \mathrm{MPa}$,

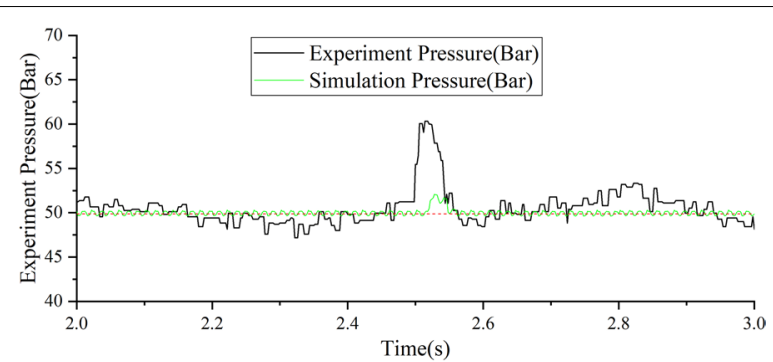

Figure 16 Backpressure control performance under flow increase

and the pressure stabilization time is about $100 \mathrm{~ms}$. Corresponding simulation results showed lighter fluctuation because of ideal pump and pressure sensor.

The pressure control results of the inlet chamber when the outlet throttling changes are shown in Figure 17. To maintain a higher inlet pressure at $5 \mathrm{MPa}$, main valve 2 spool is set as $1500 \mu \mathrm{m}$, it moves from $1500 \mu \mathrm{m}$ to $1600 \mu \mathrm{m}$ at $1 \mathrm{~s}$, causing a sudden change of the pressure in the oil inlet chamber. The pressure fluctuation is around $1.8 \mathrm{MPa}$, the pressure stabilization time is about $70 \mathrm{~ms}$, and the overshoot is about $0.1 \mathrm{MPa}$. Corresponding simulation results showed comparable results. The pressure controller developed in this paper has fast and robust dynamic performance.

\subsubsection{Experimental Test on Flow Control}

In IMC systems, the flow can be controlled independently from the pressure of the other chamber, which can improve dynamic performance of the actuator. During the test of excavator arms movement, it is found that $40-240 \mathrm{~mm} / \mathrm{s}$ is a common speed range of boom cylinder on constructed testbed in working duty cycles, corresponding rodless chamber flow is $9.5-57 \mathrm{~L} / \mathrm{min}$. So $10-50 \mathrm{~L} / \mathrm{min}$ is chosen as test range for flow control.

Typical working conditions such as low speed, high speed and transfer between them are considered in this paper. The performance of small flow step response in low speed and high speed working conditions are shown in Figures 18 and 19, respectively.

Main valve 2 spool displacement is set as $2000 \mu \mathrm{m}$ to maintain the backpressure at around $0.5 \mathrm{MPa}$. When the flow is controlled at $20 \mathrm{~L} / \mathrm{min}$, inlet chamber pressure is $0.79 \mathrm{MPa}$; stabilization time required for the flow to step from $20 \mathrm{~L} / \mathrm{min}$ to $30 \mathrm{~L} / \mathrm{min}$ is about $400 \mathrm{~ms}$, with an overshoot of about $1.5 \mathrm{~L} / \mathrm{min}$. The settling time required for the flow to step from $40 \mathrm{~L} / \mathrm{min}$ to $50 \mathrm{~L} / \mathrm{min}$ is shortened to $140 \mathrm{~ms}$, with is no overshoot. Corresponding simulation shows similar results. 


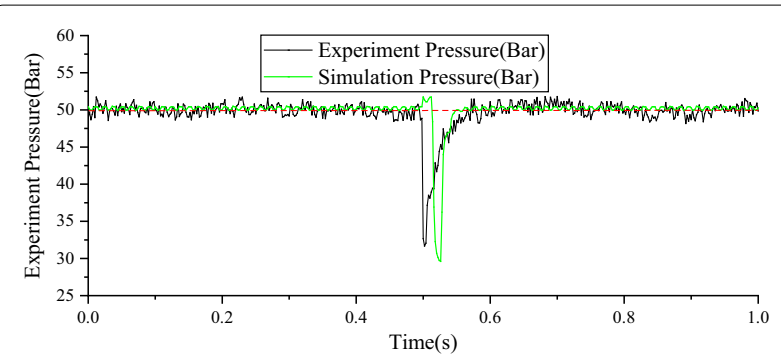

Figure 17 Inlet pressure control performance under flow decreas



Figure 18 Flow step response of the TSVSP inlet chamber from 20 to $30 \mathrm{~L} / \mathrm{min}$

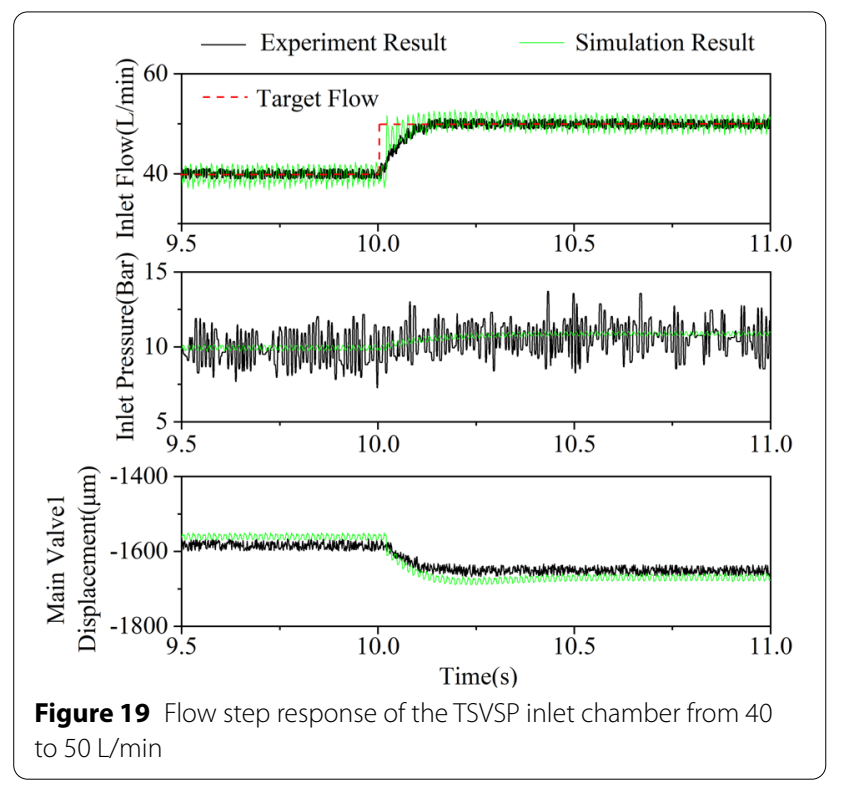

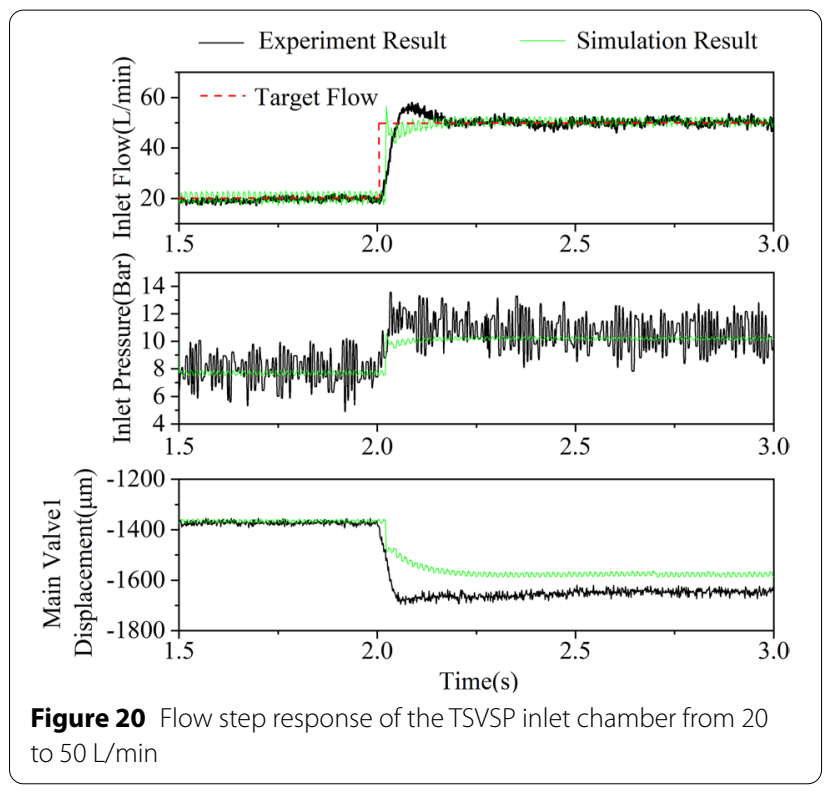

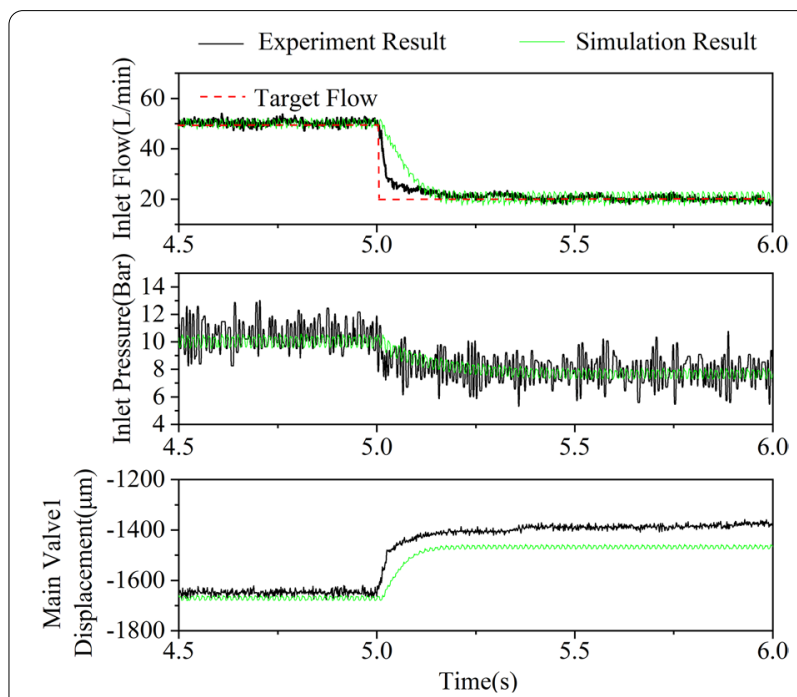

Figure 21 Flow step response of the TSVSP inlet chamber from 50 to $20 \mathrm{~L} / \mathrm{min}$

In order to test the control performance of the flow controller in low and fast speed transfer working condition, this paper further carries out a large step flow experiment, as shown in Figures 20 and 21.

The rise time of flow to step from $20 \mathrm{~L} / \mathrm{min}$ to $50 \mathrm{~L} /$ $\mathrm{min}$ is about $50 \mathrm{~ms}$, but there is an overshoot of about $6.7 \mathrm{~L} / \mathrm{min}$. The stabilization time of the entire flow step response process is about $160 \mathrm{~ms}$. When the flow is reduced from $50 \mathrm{~L} / \mathrm{min}$ to $20 \mathrm{~L} / \mathrm{min}$, the flow stabilization time is about $180 \mathrm{~ms}$ with no overshoot. Corresponding simulation showed comparable results. Compared 




with flow control performance of proportional pilot twin spools valve in Ref. [[20]] whose adjusting time for $30 \mathrm{~L} /$ min to $70 \mathrm{~L} / \mathrm{min}$ and $70 \mathrm{~L} / \mathrm{min}$ to $30 \mathrm{~L} / \mathrm{min}$ are $320 \mathrm{~ms}$ and $250 \mathrm{~ms}$, TSVSP has slightly larger steady-state error during flow control, but its dynamic characteristics in the large-scale flow control shows better dynamic characteristics.

\subsubsection{Experimental Test on Pressure and Flow Compound Control}

Pressure and flow compound control is a unique function of IMC system, which can effectively improve dynamic performance of the actuator and reduce energy consumption of the system.

TSVSP developed in this paper has a twin spools main stage structure, which can independently control inlet and outlet ports. The control algorithm schematic is shown in Figure 8. Set main valve1 to control the inlet flow while set main valve2 to control the outlet pressure. Backpressure step response experiment under stable flow and inlet flow step response experiment under stable backpressure are conducted. First experiment is suitable for adjusting the outlet dynamic damping under constant speed load to improve load movement performance, while second experiment is suitable for keeping the backpressure stable and improving system efficiency while load speed changes.

Results of backpressure step response experiment under stable flow are shown in Figure 22, the stabilization time required for the load backpressure to step from $1 \mathrm{MPa}$ to $2 \mathrm{MPa}$ is about $120 \mathrm{~ms}$. The pressure overshoot is $0.61 \mathrm{MPa}$. When the load backpressure step from $2 \mathrm{MPa}$ to $3 \mathrm{MPa}$, the pressure stabilization time is about $60 \mathrm{~ms}$, an overshoot of $0.47 \mathrm{MPa}$ appears.

Comparison with corresponding simulation and performance of proportional pilot twin spools valve in Ref. [[20]] is shown in Table 1.

In terms of flow stability, when backpressure step from $1 \mathrm{MPa}$ to $2 \mathrm{MPa}$, the flow recovery time is $80 \mathrm{~ms}$, and there is no flow oscillation during the flow recovery. When backpressure step from $2 \mathrm{MPa}$ to $3 \mathrm{MPa}$, the flow recovery time is $180 \mathrm{~ms}$.

Inlet flow step response experiment under stable backpressure is shown in Figure 23. When backpressure is maintained at $4 \mathrm{MPa}$ while inlet flow step from $20 \mathrm{~L} / \mathrm{min}$ to $30 \mathrm{~L} / \mathrm{min}$, the flow adjusting time is $120 \mathrm{~ms}$ with no obvious overshoot, the backpressure recovery time is about $140 \mathrm{~ms}$, the pressure fluctuation reaches $0.5 \mathrm{MPa}$. When the inlet flow step from $30 \mathrm{~L} / \mathrm{min}$ to $40 \mathrm{~L} / \mathrm{min}$, the flow stabilization time reduces to about $100 \mathrm{~ms}$, and the backpressure recovery time was also reduced to $60 \mathrm{~ms}$.

Table 1 Results of backpressure step response test under stable flow

\begin{tabular}{|c|c|c|c|c|}
\hline Pressure step(MPa) & Indicator & TSVSP simulation & TSVSP experiment & $\begin{array}{l}\text { Experiment } \\
\text { in Ref. } \\
{[[20]]}\end{array}$ \\
\hline \multirow[t]{3}{*}{$1-2$} & Pressure stabilization time(ms) & 100 & 120 & 110 \\
\hline & $\begin{array}{l}\text { Pressure overshoot } \\
(\mathrm{MPa})\end{array}$ & 0 & 6.1 & 5 \\
\hline & Flow recovery time(ms) & 80 & 80 & 170 \\
\hline \multirow[t]{3}{*}{$2-3$} & Pressure stabilization time(ms) & 60 & 60 & 50 \\
\hline & Pressure overshoot (MPa) & 0 & 4.7 & 4.8 \\
\hline & Flow recovery time(ms) & 100 & 180 & 500 \\
\hline
\end{tabular}




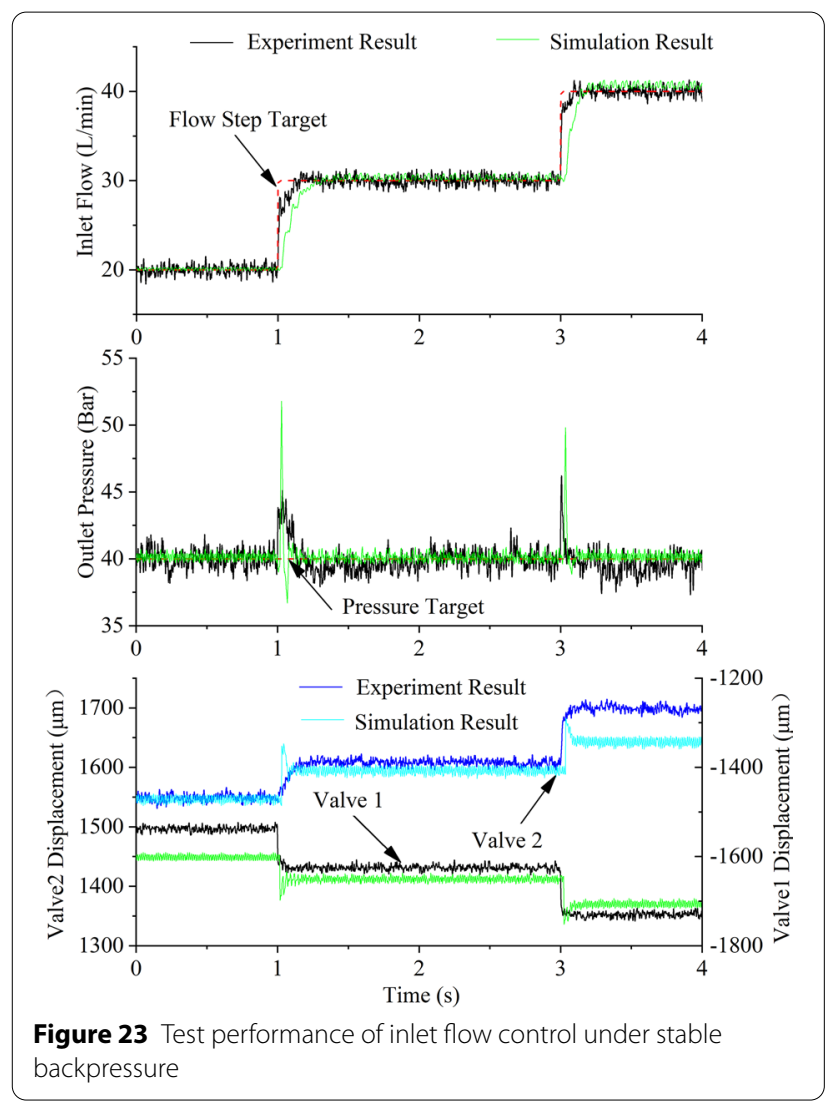

Comparison with corresponding simulation and performance of proportional pilot twin spools valve in Ref. [[20]] is shown in Table 2.

\subsection{Application on Excavator Boom Cylinder}

To verify the effectiveness of the developed TSVSP, this paper uses the excavator boom shown in Figure 24 to study pressure and flow controller performance under the resistive condition and the overrunning condition. According to the flow data during excavation test, 10-20 L/min and $20-30 \mathrm{~L} / \mathrm{min}$ are chosen as typical flow step response condition in this paper. To show the superiority of combining IMC and DHT, one traditional proportional valve is chosen to replace TSVSP in Figures 9 and 10 as matched-comparison group.

\subsubsection{Resistive Working Condition Experiment}

Boom lifting process is a typical resistive working condition. Under this working condition, main valve2 is used to control flow while main valve1 is used to control the pressure of the rod chamber. The control strategy under resistive condition is shown in Figure 25.

The result using traditional proportional valve is shown in Figures 26 and 27, where flow is obtained by linear conversion of the boom cylinder speed. According to the curve in Figure 26, when the traditional proportional valve controls the inlet flow to $10 \mathrm{~L} / \mathrm{min}$, the cylinder backpressure is nearly $6 \mathrm{MPa}$. The stabilization time required for the traditional proportional valve to complete the flow step of $10-20 \mathrm{~L} / \mathrm{min}$ is about $350 \mathrm{~ms}$. In the step control of the flow of $20-30 \mathrm{~L} / \mathrm{min}$, stabilization time is about $500 \mathrm{~ms}$, and flow overshoot is $4.5 \mathrm{~L} / \mathrm{min}$. Corresponding simulation results showed larger pressure fluctuation because of the different damping in hydraulic system.

When TSVSP is applied, compound control of inlet chamber flow and the outlet chamber pressure can be realized. Set the outlet chamber pressure to $0.5 \mathrm{MPa}$, while inlet chamber performs flow step control. The result is shown in Figures 28 and 29. The stabilization time of the flow step from $10 \mathrm{~L} / \mathrm{min}$ to $20 \mathrm{~L} / \mathrm{min}$ is about $250 \mathrm{~ms}$, and the flow overshoot is around $3 \mathrm{~L} / \mathrm{min}$. The outlet chamber pressure fluctuation caused by the flow change reaches $0.57 \mathrm{MPa}$, and the pressure recovery time is about $350 \mathrm{~ms}$.

When the flow is stepped from $20 \mathrm{~L} / \mathrm{min}$ to $30 \mathrm{~L} / \mathrm{min}$, the stabilization time is about $200 \mathrm{~ms}$, the flow overshoot is about $4 \mathrm{~L} / \mathrm{min}$, and the backpressure recovery time is $250 \mathrm{~ms}$. Corresponding simulation results showed smaller flow overshoot and pressure fluctuation because of the different damping in hydraulic system. TSVSP can realize the combined control of the pressure and flow of the boom cylinder. Pressure stability is improved compared with the proportional pilot load port independent valve. Compared with the experiment result using proportional pilot stage independent metering valve shown in Ref. [[22]] whose static error is relatively obvious,

Table 2 Results of flow step response experiment under stable backpressure

\begin{tabular}{lllll}
\hline Flow step (L/min) & Indicator & TSVSP simulation & TSVSP experiment & $\begin{array}{l}\text { Experiment } \\
\text { in Ref. } \\
{[[\mathbf{2 0}]]}\end{array}$ \\
\hline 20-30 & Flow stabilization time(ms) & 100 & 120 & 90 \\
& Pressure recovery time(ms) & 80 & 140 & 70 \\
$30-40$ & Flow stabilization time(ms) & 90 & 100 & 90 \\
& Pressure recovery time(ms) & 40 & 60 & 100 \\
\hline
\end{tabular}




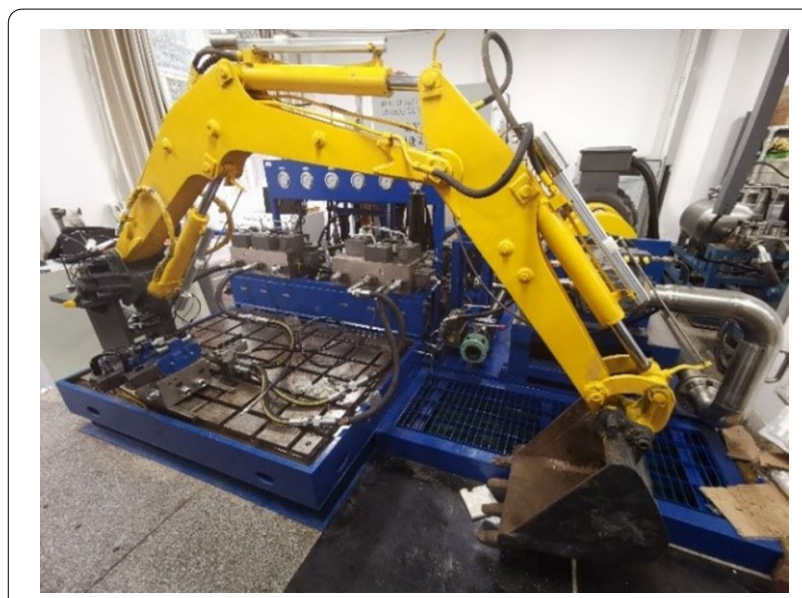

Figure 24 Excavator arm assembled on testbed
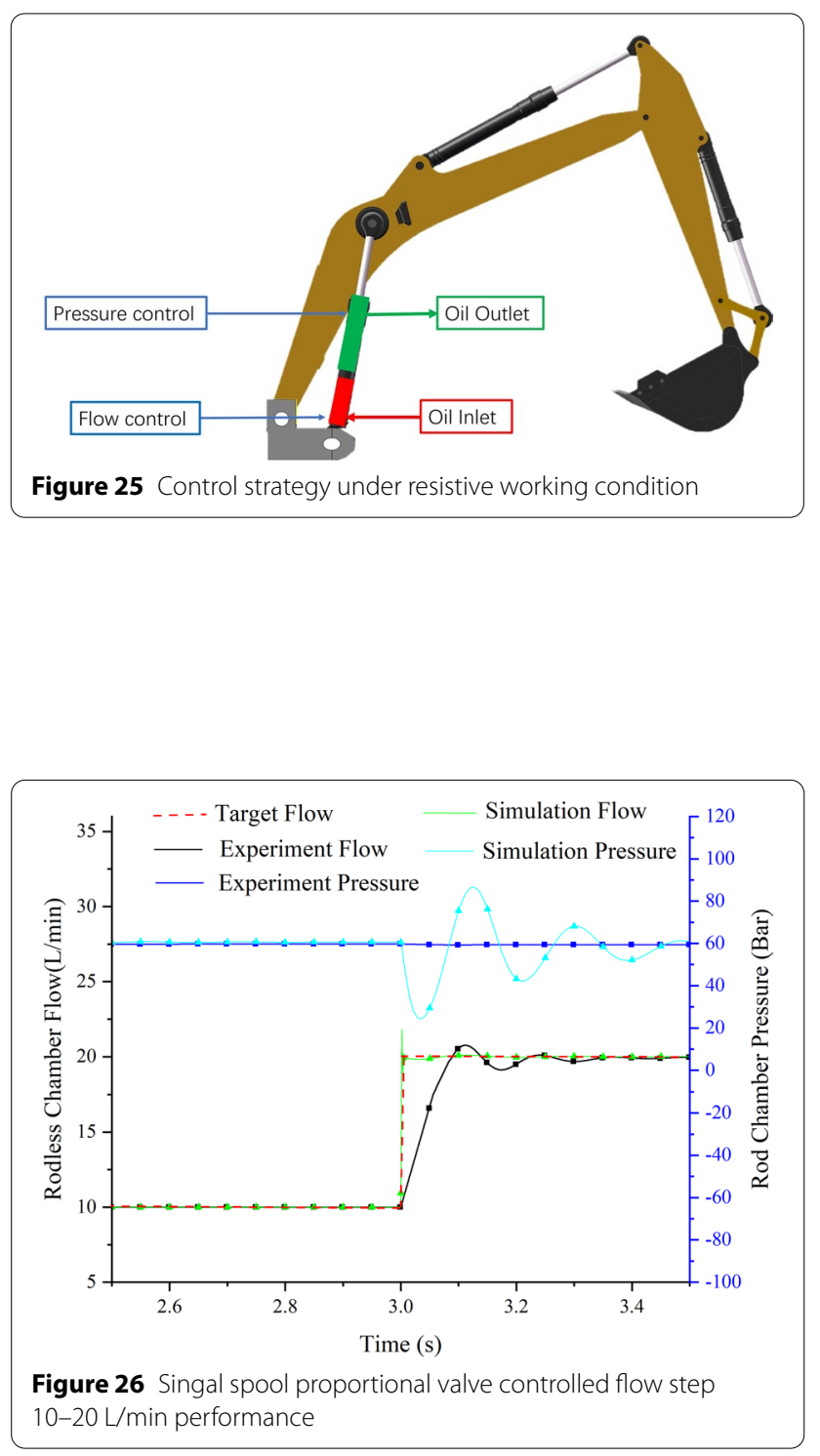

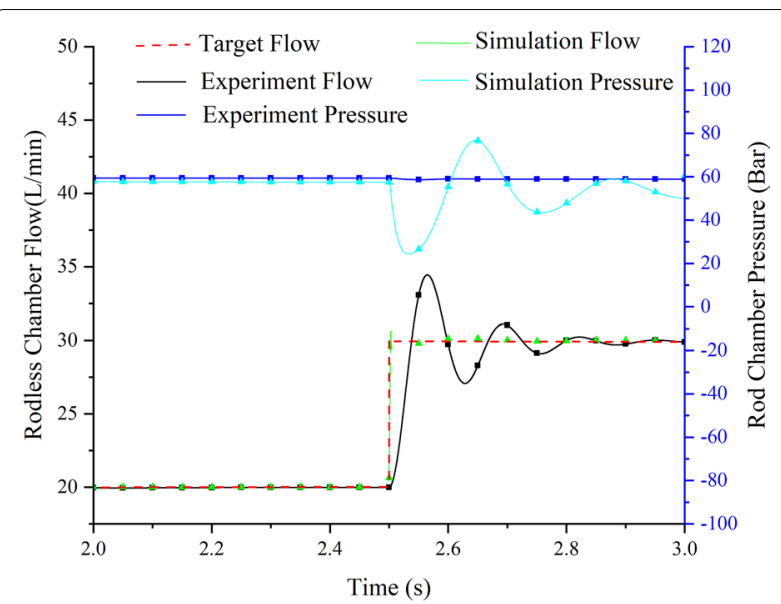

Figure 27 Singal spool proportional valve controlled flow step 20-30 L/min performance

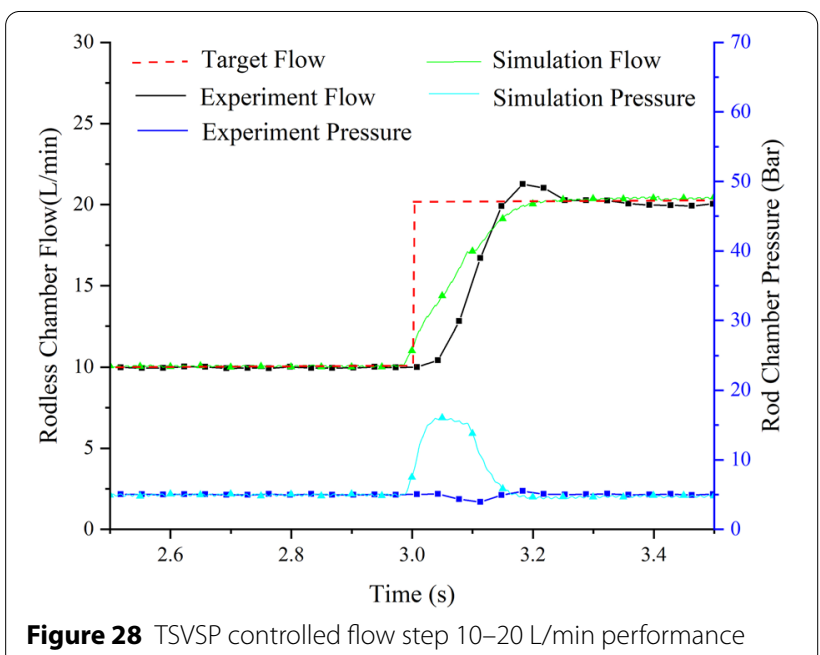

Figure 28 TSVSP controlled flow step 10-20 L/min performance



Figure 29 TSVSP controlled flow step 20-30 L/min performance 
experiment result in this paper shows smaller static error and faster response.

\subsubsection{Overrunning Working Condition Experiment}

The lowering process of the boom cylinder is a typical overrunning working condition. Under this working condition, valve2 is set to flow control mode while valve1 is set as pressure control mode as shown in Figure 30.

When traditional proportional valve is used to control the boom cylinder speed under overrunning condition as shown in Figures 31 and 32. The adjusting time for outlet flow to step from $10 \mathrm{~L} / \mathrm{min}$ to $20 \mathrm{~L} / \mathrm{min}$ and from $20 \mathrm{~L} /$ $\mathrm{min}$ to $30 \mathrm{~L} / \mathrm{min}$ is about $450 \mathrm{~ms}$ and $480 \mathrm{~ms}$, the overshoots are about $4 \mathrm{~L} / \mathrm{min}$, pressure in the rod chamber is maintained at about $10.5 \mathrm{MPa}$ which is relatively high. Corresponding simulation results showed larger pressure



Figure 30 Control strategy under overruning working condition

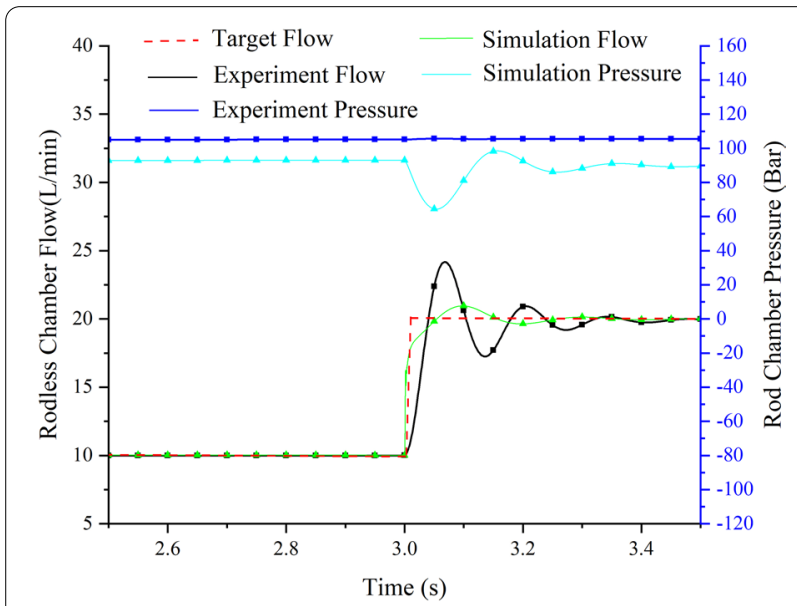

Figure 31 Singal spool proportional valve controlled flow step 10-20 L/min performance

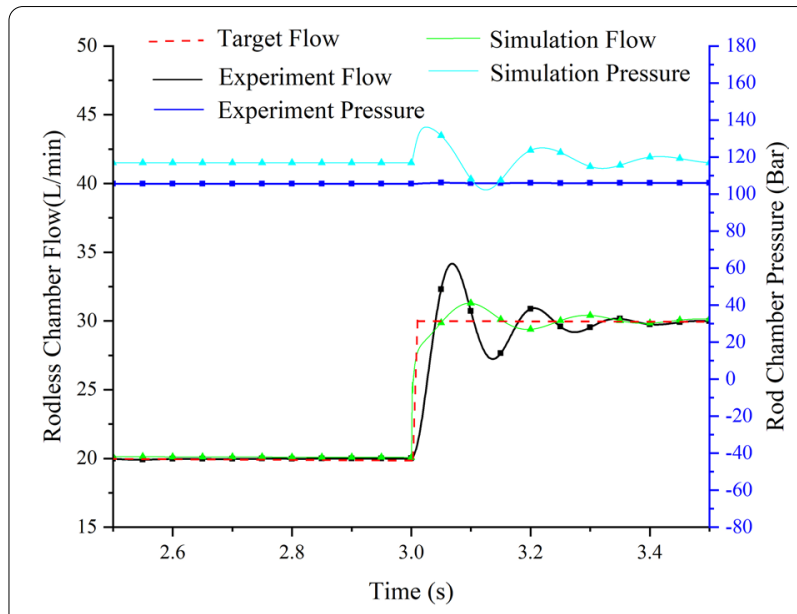

Figure 32 Singal spool proportional valve controlled flow step 20-30 L/min performance

fluctuation because of the different damping in hydraulic system.

Repeat the same experiment with TSVSP. Set the target value of the pressure controller to $0.5 \mathrm{MPa}$, experiment results are shown in Figures 33 and 34 . The adjusting time for flow from $10 \mathrm{~L} / \mathrm{min}$ to $20 \mathrm{~L} / \mathrm{min}$ is about $250 \mathrm{~ms}$, adjusting time from $20 \mathrm{~L} / \mathrm{min}$ to $30 \mathrm{~L} /$ min is about $280 \mathrm{~ms}$. Corresponding simulation stabilization time of $10-20 \mathrm{~L} / \mathrm{min} 20-30 \mathrm{~L} / \mathrm{min}$ are about $250 \mathrm{~ms}$ and $260 \mathrm{~ms}$, respectively. Corresponding simulation results showed smaller flow overshoot and pressure fluctuation because of the different damping in hydraulic system. Compared with the experiment result using proportional pilot stage independent metering valve shown in Ref. [[23]] whose adjusting time is about $500 \mathrm{~ms}$, experiment result in this paper has shorter adjusting time.

\section{Conclusions}

This paper presents a TSVSP which combins IMC technology with DHT. The conclusions are given as follows:

(1) Mathematical and simulation models of TSVSP controlled cylinder hydraulic system are constructed, based on which compatible system fuzzy controller is designed.

(2) Together with switching controlled pilot stage HSV, step response tests as well as stability tests of pressure and flow in both meter-in and meter-out chambers are conducted, furthermore, IMC performance of excavator cylinder during powered extension and powered retraction is considered in this case. Rising time of flow response in excavator cylinder can be controlled within $200 \mathrm{~ms}$, meanwhile, the recovery time of rod chamber 




Figure 33 TSVSP controlled flow step 10-20 L/min performance

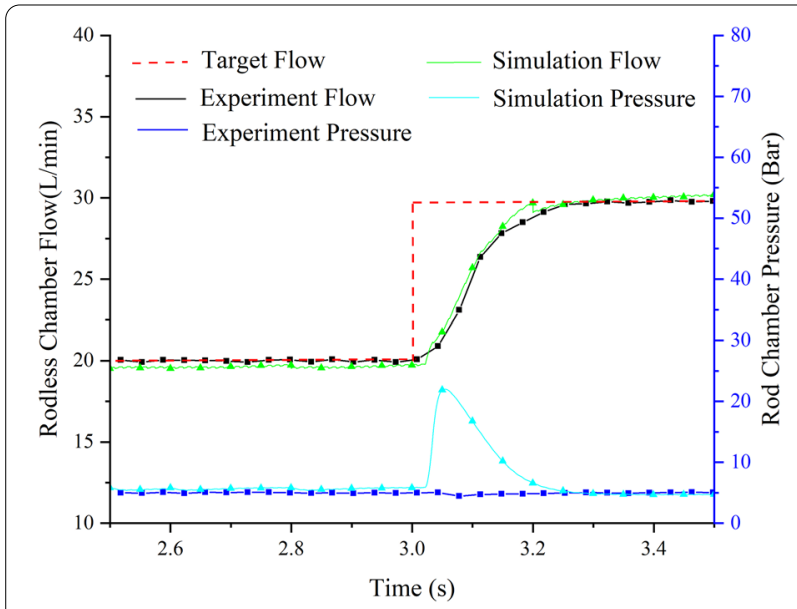

Figure 34 TSVSP controlled flow step 20-30 L/min performance

pressure under suddenly changed condition is optimized within $250 \mathrm{~ms}$.

(3) Experiment and simulation results show that compared with traditional proportional valve and proportional pilot twin spools valve, IMC system based on TSVSP shows faster and more robust dynamic performance under different working conditions, proving that it has huge potential in the application on excavators.

\section{Acknowledgments}

Not applicable.

\section{Authors' Contributions}

QZ was in charge of proposing the conception and experiment; HB wrote the draft manuscript and conducted simulation; $\mathrm{YL}$ and $\mathrm{HH}$ assisted with experiment and data analysis; BZ and HY checked and improved the manuscript in writing. All authors read and approved the final manuscript.

\section{Authors' Information}

Qi Zhong received his PhD degree from Zhejiang University, Hangzhou, China, in 2019. He is now an associate researcher in Zhejiang University of technology, China.

Huiming Bao is currently a PhD candidate in Zhejiang University, China. Yanbiao Li is currently a Professor in Zhejiang University of Technology, China. Haocen Hong received his PhD degree in mechanical and electrical engineering from Zhejiang University in 2019. He is currently an assistant researcher in Zhejiang University, China.

Bin Zhang received his PhD degree from Zhejiang University, China, in 2009. He is currently an associate researcher in Zhejiang University, China.

Huayong Yang is currently a Professor in Zhejiang University. He has been a member of the Chinese Academy of Engineering since 2013

\section{Funding}

Supported by National Natural Science Foundation of China (Grant Nos. 52005441, 51890885), open Foundation of the State Key Laboratory of Fluid Power and Mechatronic Systems (Grant No. GZKF-201906), Zhejiang Province Natural Science Foundation of China (Grant No. LQ21E050017) and China Postdoctoral Science Foundation (Grant Nos. 2021 M692777, 2021T140594).

\section{Competing Interests}

The authors declare no competing financial interests.

\section{Author Details}

${ }^{1}$ State Key Laboratory of Fluid Power and Mechatronic Systems, Zhejiang University, Hangzhou 310027, China. ${ }^{2}$ College of Mechanical Engineering, Zhejiang University of Technology, Hangzhou 310023, China. ${ }^{3}$ Key Laboratory of Special Purpose Equipment and Advanced Processing Technology, Ministry of Education \& Zhejiang Province, Zhejiang University of Technology, Hangzhou 310023, China.

Received: 9 March 2021 Revised: 30 August 2021 Accepted: 4 September 2021

Published online: 20 September 2021

\section{References}

[1] A Sitte, J Weber. Structural design of independent metering control systems. 13th Scandinavian International Conference on Fluid Power, Linköping, Sweden, June 3-5, 2013: 261-270.

[2] B Yao, L Song. Energy-saving control of hydraulic systems with novel programmable valves. Proceedings of the 4th World Congress on Intelligent Control and Automation, Shanghai, China, June 10-14, 2002: 3219-3223.

[3] L Song, B Yao. Energy-saving control of single-rod hydraulic cylinders with programmable valves and improved working mode selection. SAE Transactions, 2002, 111: 51-61

[4] P Opdenbosch, N Sadegh, W Book, et al. Auto-calibration based control for independent metering of hydraulic actuators. 2011 IEEE International Conference on Robotics and Automation. Shanghai, China, May 9-13, 2011: 153-158.

[5] L Lyu, Z Chen, B Yao. Energy Saving Motion Control of Independent Metering Valves and Pump Combined Hydraulic System. IEEE/ASME Transactions on Mechatronics, 2019, 24(5): 1909-1920.

[6] G Chen, J Wang, S Wang, et al. Indirect adaptive robust dynamic surface control in separate meter-in and separate meter-out control system. Nonlinear Dynamics, 2017, 90: 951-970.

[7] M Cheng, T Sun, R Q Ding, et al. Pump/valves coordinate control of the independent metering system for mobile machinery. Automation in Construction, 2015, 57: 98-111.

[8] R Ding, B Xu, J H Zhang, et al. Self-tuning pressure-feedback control by pole placement for vibration reduction of excavator with independent metering fluid power system. Mechanical Systems and Signal Processing 2017, 92: 86-106. 
[9] B Liu, L Quan, L Ge. Research on the performance of hydraulic excavator boom based pressure and flow accordance control with independent metering circuit. Proceedings of the Institution of Mechanical Engineers, Part E: Journal of Process Mechanical Engineering, 2017, 231(5): 901-913.

[10] X Zhang, S Qiao, L Quan, et al. Velocity and position hybrid control for excavator boom based on independent metering system. IEEE Access, 2019, 7: 71999-72011.

[11] J Shi, Q Long, X Zhang, et al. Electro-hydraulic velocity and position control based on independent metering valve control in mobile construction equipment. Automation in Construction, 2018, 94: 73-84.

[12] KX Ba, B Yu, Z J Gao, et al. An improved force-based impedance control method for the HDU of legged robot. ISA Transactions, 2019, 84: 187-205.

[13] M Linjama. Digital fluid power: State of the art. The 12th Scandinavian International Conference on Fluid Power, Tampere, Finland, 2011: 18-20.

[14] B Winkler, A Ploeckinger, R Scheidl. A novel piloted fast switching multi poppet valve. International Journal of Fluid Power, 2011, 11(3): 7-14

[15] CWen, ZY Wu, XWang, et al. Performance research of cartridge valve controlled by high-speed on/off valve. Machine Tool \& Hydraulics, 2012, 40(23): 61-63. (in Chinese)

[16] T Li, J Huang, Y Bai, et al. Characteristics of a piloted digital flow valve based on flow amplifier. International Conference on Fluid Power and Mechatronics, Harbin, China, 2015: 200-204.

[17] SWang, B Zhang, Q Zhong, et al. Study on control performance of pilot high-speed switching valve. Advances in Mechanical Engineering, 2017, 9(7): 1-8.
[18] H Shi, ZY Liu, HTWang. Design and performance analysis of hydraulic switching valve driven by magnetic shape memory alloy. Advances in Mechanical Engineering, 2021, 13(5):1-15.

[19] Q Zhong, X L Wang, G Xie, et al. Analysis of Dynamic Characteristics and Power Losses of High Speed on/off Valve with Pre-Existing Control Algorithm. Energies, 2021, 14(16): 4901.

[20] Q Zhong, B Zhang, H M Bao, et al. Analysis of pressure and flow compound control characteristics of an independent metering hydraulic system based on a two-level fuzzy controller. Journal of Zhejiang UniversityScience A, 2019, 20(3): 184-200.

[21] B Zhang, Q Zhong, J E Ma, et al. Self-correcting PWM control for dynamic performance preservation in high speed on/off valve. Mechatronics, 2018, 55: $141-150$

[22] K A Tabor. A novel method of controlling a hydraulic actuator with four valve independent metering using load feedback. 2005 SAE Commercial Vehicle Engineering Conference, Chicago, USA, November 1-3, 2005: 3639.

[23] R Ding, B Xu, J Zhang, et al. Bumpless mode switch of independent metering fluid power system for mobile machinery. Automation in Construction, 2016, 68: 52-64.

\section{Submit your manuscript to a SpringerOpen ${ }^{\circ}$ journal and benefit from:}

- Convenient online submission

- Rigorous peer review

- Open access: articles freely available online

- High visibility within the field

- Retaining the copyright to your article

Submit your next manuscript at $\boldsymbol{\nabla}$ springeropen.com 